\title{
LA AGRICULTURA RIOJANA EN LA CRISIS FINISECULAR
}

\author{
Jesús Javier Alonso Castroviejo*
}

\section{Planteamiento**}

La agricultura era la principal actividad de los riojanos y el sector que más aportaba al P.I.B durante todo el siglo XIX. Sin embargo, en la actualidad, nuestros conocimientos sobre esta parcela de nuestra historia económica son más bien fragmentarios, toscos e incompletos. Si empezamos por la estructura agraria, apenas si disponemos de datos de tres municipios en fechas próximas a finales de siglo, objeto del presente trabajo, y que van a ser la base del estudio que ahora presento. Tampoco la evolución de la variable precios de los productos agrarios es conocida, ni las coyunturas por las que atravesó el precio de la tierra, o la curva de la tasa de arrendamiento de la misma. Lo mismo nos sucede con la dimensión social del mundo agrario, ya que ignoramos la estratificación y cuantificación de los distintos grupos campesinos -desde grandes propietarios a jornaleros-. Tan sólo conocemos con suficiente exactitud la utilización del terrazgo y la implantación de los distintos cultivos, así como las superficies dedicadas a cada uno de ellos.

Ante tal cúmulo de insuficiencias, la pretensión de este artículo tiene que ser necesariamente modesta y limitarse a presentar algunos datos inéditos -pocosy una síntesis o reelaboración de aquellas informaciones dispersas en distintas publicaciones' ${ }^{1}$ y que nos permitan hacernos una idea aproximada de lo que

* Universidad de La Rioja

** Este artículo forma parte del trabajo colectivo La Rioja ante la crisis de fin de siglo, financiado por la Universidad de La Rioja durante los años 1997 y 1998 (API-97/A03 y API98/A10).

1. Los trabajos más importantes sobre el mundo agrario riojano hacia finales del XIX son los siguientes: Gallego, D.: La producción agraria de Álava, Navarra y La Rioja desde mediados del siglo XIX a 1935. Madrid, 1986. y "El sector agrario riojano (1855-1935): de la especialización vitícola a la diversificación de la producción agraria". Brocar. Logroño,1987. Bermejo, F.: La Diputación provincial de La Rioja. Logroño,1989. López, P.: Élites y poder. 
pudo acontecer en La Rioja en torno a fin de siglo XIX, tan cargado de simbolismo, tanto por cuestiones de índole político como económico, social e ideológico.

No creo que sea necesario realizar una detalla crítica de las fuentes documentales utilizadas, que se reducen en este caso a los amillaramientos de las poblaciones de Treviana, Azofra y Logroño, cuyos resultados, convenientemente tratados estadísticamente, van a ser aceptados sin más puntualizaciones, pues han sido numerosas las ocasiones en la que los investigadores se han referido a ellas y en esta ocasión no se va a trabajar con ninguna fuente original, que no haya sido utilizada antes por otros historiadores de la agricultura.

La exposición se va a estructurar en tres partes. En la primera de ellas se compararán los amillaramientos de las tres poblaciones citadas y a pesar de su escasa representatividad se intentarán extraer algunas conclusiones que sean más hipótesis hacia el futuro que aseveraciones sólidas. En la segunda parte se mostrará una síntesis de lo que mejor conocemos, la evolución de las superficies agrarias y de sus utilizaciones para distintos cultivos dependiendo de las coyunturas del mercado. Por último se dedicará un apartado especial al viñedo y la crisis filoxérica, omnipresente y recurrente cuando se estudian estas fechas. En el tintero quedan temas que nos hubiera gustado ofrecer, pero que el estado actual de la investigación hace imposible, por cuanto no hay trabajos que los hayan abordado y con los actuales derroteros de la historiografía nacional parece que tampoco se abordarán en el futuro, pues a las jóvenes generaciones de investigadores parece que les atraen más otras formas de hacer historia.

\section{Estrucuturas agrarias: los casos de Logroño, Azofra y Treviana}

Empezaremos por la más pequeña de las tres poblaciones, Azofra² . En 1887 contaba con 534 habitantes y la extensión de su término municipal alcanzaba las 1.176 hectáreas. Pertenecía al partido judicial de Nájera y su altitud sobre el nivel del mar era de 560 metros.

\footnotetext{
Cambio estructural y dinámica política bajo el caciquismo liberal. La Rioja, 1890-1923. Zaragoza. Tesis doctoral inédita, 1997 y "Reforma agraria y revolución liberal en Logroño durante la edad contemporánea". Brocar, Universidad de La Rioja, 1999. Provedo, J.: "La filoxera en la provincia de Logroño. Destrucción del viñedo y su reconstitución". Berceo. Logroño, 1987. Barco, E.: Del "oidium" a la edad de oro. Los precios del vino en La Rioja (1855-1874). Logroño, Tesis de licenciatura inédita. Universidad de La Rioja, 1998. Ibáñez, S. y Alonso, J.:"Especialización agraria en el Alto Ebro (La Rioja): la cultura del vino 1500-1900". Brocar. Logroño, 1996. Oestreicher, A.: "Algunos aspectos de la historia del sector vitivinícola riojano, 18601915" en Berceo. Logroño, 1994 y "La crisis filoxérica en España". Hispania. Madrid,1996.

2. Los datos que se presentan en los siguientes cuadros fueron extraídos de la documentación original por Pilar Camacho, alumna de doctorado. Le agradezco profundamente el que me haya permitido depurar la información original y utilizarla para este trabajo.
} 
Desgraciadamente no contamos con datos que nos indiquen la estructura socio-profesional del pueblo, aunque hay que suponer, dado el elevado número de propietarios que declaran tierra, que la inmensa mayoría de la población se dedicara à las tareas agropecuarias.

En primer lugar se va a analizar la estructura de la propiedad, tal y como queda reflejada en el cuadro 1 y en su representación, la curva de Lorenz, en el gráfico 1.

Cuadro 1. Estructura de la propiedad. Azofra 1894

\begin{tabular}{|l|r|r|r|r|}
\hline & Prop. & $\%$ & Sup. & $\%$ \\
\hline$<1$ (has.) & 17 & 9,3 & 5,2 & 0,6 \\
\hline $1,01-2$ & 24 & 13,2 & 20,7 & 2,3 \\
\hline $2,01-4$ & 36 & 19,8 & 53,2 & 5,9 \\
\hline $4,01-8$ & 41 & 22,5 & 115,3 & 12,8 \\
\hline $8,01-16$ & 34 & 18,7 & 199,8 & 22,1 \\
\hline $16,01-32$ & 22 & 12,1 & 238,9 & 26,4 \\
\hline$>32,01$ & 8 & 4,4 & 270,8 & 30,0 \\
\hline Total & 182 & 100 & 903,9 & 100 \\
\hline & \multicolumn{5}{|c}{ Indice de Gini: 0,57} \\
\hline
\end{tabular}

Tanto el cuadro como el gráfico expresan una misma realidad, una distribución de la propiedad no excesivamente polarizada, con un I.G. de 0,57, notablemente inferior al de los otros dos municipios que vamos a estudiar. En el actual estado de nuestros conocimientos resulta aventurado proponer cualquier tipo de explicación. Sabemos que los grandes procesos de redistribución de la tierra realizados durante el siglo XIX, las desamortizaciones, no modificaron sustancialmente las estructuras agrarias preexistentes, aunque si es cierto que propiciaron modestas tendencias hacia grados mayores de concentración. Las ventas de bienes desamortizados entre 1837 y 1847, tanto en Azofra como en Treviana fueron muy escasas, pues no superaron en ningún pueblo las cincuenta hectáreas, superficie muy poco representativa como para poder cambiar las estructuras preexistentes. Otros factores deben ser estudiados, estructura de clases, naturaleza señorial o real de los términos municipales, densidad y presión sobre la tierra, ocupaciones alternativas de la población activa..., aspectos que en este momento desconocemos. Sólo un indicador nos ofrece diferencias notables entre Azofra y Treviana: la densidad de población. Mientras que en Azofra es de 45 habitantes por $\mathrm{km}^{2}$ en 1887, en Treviana es de 33 habitantes en la misma fecha. Puede pensarse que una mayor densidad, con porcentajes de ocupación por sectores profesionales similares, pues ambos pueblos estaban volcados hacia la agricultura, obligara a una más igualitaria distribución de la propiedad, pues todos los vecinos buscarían con ahínco la categoría de propietarios. Con menores densi- 
dades la presión sobre la tierra sería menor y por lo tanto también la necesidad de los habitantes. Si a eso se añade la extensión del término municipal, cuanto más pequeño, mayores dificultades para acumular grandes superficies. Otro dato que puede confirmar esta impresión es la presencia de propietarios forasteros: en municipios de alta presión sobre la tierra su presencia sería pequeña, mientras que en aquellos con una menor densidad su protagonismo pudiera incrementarse. Las cifras de Azofra y Treviana confirman esta hipótesis: en Azofra los forasteros son propietarios del $17 \%$ del terrazgo cultivado, mientras que en Treviana lo son del $43 \%$. Una diferencia apreciable, como se ve. Aunque para que esta intuición pueda explicar algo es necesario, sin duda, un mayor muestreo de poblaciones en las que se repita esta relación.

El municipio de Treviana presentaba una estructura de la propiedad bastante distinta. En efecto, el índice de concentración se establece en el 0,71, una cifra elevada que denota la desigual apropiación del bien tierra. Situado en la frontera con la provincia de Burgos, tenía 1.160 habitantes en 1887 y su jurisdicción se extendía por 3.465 hectáreas, una extensión superior a la media provincial $^{3}$. Pertenecía al partido judicial de Haro, aunque era uno de los términos con menor protagonismo del viñedo de todos los que componían el partido ${ }^{4}$. En el cuadro 2 y el gráfico 2 se representan estas magnitudes ${ }^{5}$.

Cuadro 2. Estructura de la propiedad. Treviana 1879

\begin{tabular}{|l|c|c|c|c|}
\hline & Prop. & $\%$ & Sup. & $\%$ \\
\hline$<1$ (has.) & 168 & 44,6 & 69,2 & 4,21 \\
\hline $1,01-2$ & 70 & 18,6 & 100,2 & 6,09 \\
\hline $2,01-4$ & 48 & 12,7 & 140,5 & 8,54 \\
\hline $4,01-8$ & 36 & 9,5 & 207,5 & 12,6 \\
\hline $8,01-16$ & 31 & 8,2 & 329,7 & 20 \\
\hline $16,01-32$ & 13 & 3,4 & 299,0 & 18,2 \\
\hline$>32,01$ & 11 & 2,9 & 499,3 & 30,3 \\
\hline Total & 377 & 100 & $1.645,4$ & 100 \\
\hline & \multicolumn{3}{|c|}{ indice de Gini:0,71 } \\
\hline
\end{tabular}

Lo que más puede sorprender de los datos ofrecidos para Treviana es el elevado número de campesinos que declaran propiedades inferiores a una hectárea, o lo que es lo mismo unas cinco fanegas. Casi la mitad de los declarantes poseían sólo el $4,2 \%$ de la tierra. Parece obvio que no podían vivir

3. La superficie media municipal en la actualidad es de 2.893 hectáreas.

4. Barco, E.: Del "oidium" a la edad de oro..., p. 32, mapa.

5. Los datos fueron recogidos del amillaramiento de 1879 por los alumnos Diego Téllez y Rubén Pablos, para la elaboración de un trabajo de curso. Les agradezco el permiso concedido para utilizarlos en esta investigación. 
exclusivamente de sus explotaciones y que se tendrían que contratar como arrendatarios o jornaleros para otros señores, en una zona donde el protagonismo del viñedo demandaba mucha mano de obra. A pesar de que a primera vista pueda parecer irracional el mantenimiento de estas pequeñas explotaciones, no lo es, pues jugaban un importantísimo papel en la fijación del campesino a la tierra. El ser propietarios los ataba a su tradición y frenaba los impulsos que pudieran tener hacia la emigración. Pero como no tenían suficiente tierra para la autoreproducción, los grandes propietarios los contrataban para las labores estacionales, sirviendo siempre como "ejército de reserva" si las migraciones golondrina no aportaban la necesaria mano de obra para todas las labores agrarias. Ante esta radical dualidad no debe costarnos demasiado imaginar las dificultades de estos pequeños campesinos cuando la filoxera arrasó sus propiedades y también las de quienes les contrataban. Su capacidad "empresarial" para resistir tenía que ser nula y la falta de alternativas les empujó al abandono, pues al ser todas parcelas de secano $^{6}$ los cultivos sustitutivos, intensivos en capital y trabajo y que necesitaban el regadío para prosperar, no fueron nunca una solución al desastre finisecular.

Por último el municipio de Logroño. La capital de la provincia aún mantenía a finales del siglo XIX un sector agrario considerable y la extensión dedicada al laboreo no había dejado de crecer, a pesar de la paulatina reducción de la población activa del sector primario, que en 1900 representaban el 31\% de los totales activos. El cuadro 3 y el gráfico 3 muestran los datos referidos al grado de concentración de la propiedad.?

Cuadro 3. Estructura de la propiedad. Logroño 1892-1893

\begin{tabular}{|l|c|c|c|c|}
\hline Logroño & Prop. & $\%$ & Sup. & $\%$ \\
\hline$<1$ (has.) & 223 & 31,4 & 122,2 & 2,04 \\
\hline $1,01-2$ & 137 & 19,3 & 205,8 & 3,43 \\
\hline $2,01-4$ & 112 & 15,8 & 355,4 & 5,92 \\
\hline $4,01-8$ & 87 & 12,3 & 513,4 & 8,55 \\
\hline $8,01-16$ & 76 & 10,7 & 857,4 & 14,3 \\
\hline $16,01-32$ & 49 & 6,9 & $1.095,0$ & 18,2 \\
\hline$>32,01$ & 26 & 3,7 & $2.855,4$ & 47,6 \\
\hline Total & 710 & 100 & $6.004,6$ & 100 \\
\hline & \multicolumn{2}{|c|}{ indice de Gini: 0,73} \\
\hline
\end{tabular}

6. En 1990, el regadío del término municipal de Treviana sólo alcanzaba las 26 hectáreas. Cien años antes era inexistente. Gobierno de La Rioja: Estadística agraria regional, 1990. Logroño, 1991, p. 76

7. Los datos en López, P.: "Reforma agraria..." 
El proceso de concentración de la propiedad agraria en el término municipal fue constante desde, al menos, la segunda mitad del siglo XVIII . Los datos que conocemos para 1751 y $1818-0,62$ y 0,67 respectivamente- son inferiores al que ahora se ofrece, lo que nos puede indicar que la tierra siguió siendo una inversión atractiva durante todo el siglo XIX, a pesar de las nuevas orientaciones burocráticas y de servicios que estaba experimentando la ciudad desde su nombramiento como capital de la provincia, y que al menos en teoría, podían servir a los capitalistas burgueses como sectores atractivos donde invertir sus excedentes de capital.

El crecimiento del sector terciario parece indicar que las estrategias del capital fueron en la doble dirección indicada: tierra y servicios, con un sector industrial aun atrasado y dependiente completamente de la agricultura para su rentabilidad.

Al no ser la tierra el factor productivo principal podemos suponer que estaba liberada de las tensiones sociales que necesariamente acompañaban a aqueIlas poblaciones que habían hecho del agro su única manera de vida. Por lo tanto no debe extrañarnos que el proceso de concentración no supusiera conflictos importantes y que tampoco la crisis finisecular tuviera las trágicas consecuencias que hemos visto para otras comarcas riojanas.

La estructura social del campo riojano esta por hacer. No conocemos con exactitud la composición de cada grupo social, ni cuantitativamente ni, por supuesto, las relaciones que se establecían entre ellos. El cuadro 4 intenta, con unas pocas cifras acercarse a esa problemática. Para ello se han recogido los datos que aportaban los censos oficiales sobre la ocupación profesional de los riojanos en esas fechas. Las cifras de Logroño conjugan el número de propietarios que ofrece el amillaramiento estudiado con las personas que se declaran trabajadores de la tierra en el censo de 1900. De tan pocas informaciones podemos, al menos, extraer algunas hipótesis.

Cuadro 4. Estructura social de los agricultores, La Rioja

\begin{tabular}{|l|r|r|r|r|r|r|}
\hline & 1860 & $\%$ & $1900^{*}$ & $\%$ & 1920 & $\%$ \\
\hline Propietarios & 16.303 & 38,0 & 710 & 27,3 & 15.953 & 36,2 \\
\hline Arrendatarios & 5.489 & 12,8 & & & & \\
\hline Jornaleros & 21.090 & 49,2 & 1.894 & 72,7 & 28.059 & 63,8 \\
\hline Total & 42.882 & & 2.604 & & 44.012 & \\
\hline
\end{tabular}

* Exclusivamente la ciudad de Logroño.

Las cifras nos indican que casi dos tercios de los campesinos eran asalariados que no disfrutaban de ningún tipo de propiedad. En las dos fechas extremas este porcentaje es curiosamente coincidente, lo que puede indicar que en épocas de tranquilidad productiva la estructura social agraria sufría pocas modificaciones, estableciéndose una relación entre propietarios y asalariados muy estable. Sin 
embargo, en Logroño, en 1900, antes del impacto de la crisis y por lo tanto, en el momento de casi máximo apogeo de la fiebre vitivinícola el número de jornaleros se eleva a casi tres cuartas partes del sector. Supongo que en zonas de mayor presencia de la vid el porcentaje podía todavía ser algo mayor, lo que puede ser un factor que ayude a comprender la conflictividad detectada tan magistralmente por Carlos Gil en sus trabajos ${ }^{8}$. Pero estos datos no ofrecen la verdadera situación del campo riojano, pues hay que suponer que no todos los propietarios eran autosuficientes y podían vivir de sus parcelas. Si consideramos que sólo a partir de una propiedad superior a las diez hectáreas se puede pensar en la autosubsistencia ${ }^{9}$ y tomamos los datos recogidos por los tres amillaramientos, podemos concluir que aproximadamente nada más que el $20 \%$ de los propietarios no necesitaban emplearse como asalariados a otros agricultores. Extrapolando esta cifra a las que se facilitan en el cuadro, se puede deducir que el 90\% de los campesinos tenían que ofrecerse como jornaleros en algunas fases de los trabajos agrícolas, mientras que el $10 \%$ restante podía definirse verdaderamente como propietario-empresario agrario. Esto no significa que los comportamientos políticos de esa masa asalariada fueran únicos, ni que tan siquiera hubiera cierta coincidencia en sus estrategias y actuaciones. Más poderosa que la miseria o la subordinación, era la línea que dividía al propietario -por muy pequeño que fuese- del simple jornalero y sus intereses, tan coincidentes en tantos aspectos, nunca llegaron a confluir en acciones reivindicativas comunes.

\section{Utilización del suelo en Azofra, Logroño y Treviana}

Frente a las pretendidas visiones inmovilistas del campo español, que han dominado durante décadas los enfoques de los investigadores, los estudios del GEHR fueron demostrando que la agricultura nacional era capaz de alimentar a un número creciente de población, de introducir innovaciones y de ir perfilando una especialización regional en la que se dibujaron zonas de exportación y zonas de producción para el mercado nacional. El mayor lastre, la nula mecanización de las labores, se justifica por la abundante mano de obra que hasta fechas muy cercanas a hoy ha mantenido el sector agrario. Si un jornalero era más barato que una segadora, o que un arado de vertedera, ¿para qué el propietario iba a invertir en esos utensilios?. Las razones por las cuales se produjo esa situación escapan a las pretensiones de este trabajo, pero parece claro que no se le debe culpabilizar en exclusiva a la agricultura de ser el factor retarda-

8. Gil, C.: Protesta popular y movilización social en La Rioja, 1890-1936. Zaragoza, Tesis Doctoral inédita, 1998.

9. Obviamente esta cifra es aproximada, pues se tendrían que valorar muchos aspectos para llegar a conocer con exactitud la cantidad de tierra necesaria para que un campesino no tenga necesidad de contratarse como jornalero para otro propietario. Aún así, algunos estudios cifran en torno a las diez hectáreas la superficie mínima, introduciéndose en el análisis la calidad, la posibilidad de regadío, etc. 
tario de la modernización nacional. La burguesía industrial ultraproteccionista y el crónico déficit estatal, motivado por políticas fiscales que permitían la evasión indiscriminada y no recaudaban las cantidades necesarias, son otras razones que hay que tener en cuenta y valorar en su justa medida.

En el caso riojano, la paulatina introducción de un sector agroindustrial puntero en la península puede ser un perfecto indicativo de que los campesinos no se quedaron lamiéndose las heridas de una revolución burguesa expropiatoria, invocando viejas comunidades de aldea, sino que fueron adaptándose a las nuevas realidades del mercado impulsando la industria conservera y transformando durante la segunda mitad del siglo XIX el sector vitivinícola para conquistar mercados hasta entonces insospechados para el vino de Rioja.

En primer lugar se va a estudiar la utilización del suelo que muestran los amillaramientos hasta ahora utilizados y se va a comparar con la superficie que se recoge en la encuesta agraria de $1881^{10}$. En los casos de Logroño y Azofra, dado el tiempo transcurrido entre los datos de ambos interrogatorios se encontrarán diferencias sustanciales. No así en el caso de Treviana, ya que sólo transcurrieron tres años entre una y otra averiguación y las diferencias observables pueden deberse más a deficiencias de realización que a verdaderos cambios productivos. Para homogeneizar los datos se han realizado grandes agrupaciones de cultivos y en el caso del municipio de Logroño no se ha considerado oportuno desagregar las superficies de regadío y las de secano.

Las diferencias que se aprecian en los aprovechamientos de Treviana son las más difíciles de explicar, pues parece imposible admitir unos incrementos de la superficie agraria útil de cuatrocientas hectáreas en apenas tres años. Es posible que el carácter fiscal del amillaramiento de 1879 empujara a los propietarios a un ocultamiento de explotaciones y que en 1881 algunas de estas volvieran a aflorar. Aunque lo que también puede resultar paradójico es que la proporción entre viñedo y cereal se mantenga con muy ligeras modificaciones en ambos documentos. En todo caso, la tendencia que se dibuja contrasta con la de los otros dos pueblos, donde el crecimiento del viñedo es superior al del cereal.

Cuadro 5. Aprovecchamientos del suelo. Azofra, Logroño y Treviana

\begin{tabular}{|l|r|r|r|r|r|}
\hline Azofra & Parcelas & Superficie & $\%$ & $1881^{*}$ & $\%$ \\
\hline Huerta & 4 & 0,5 & 0,1 & & \\
\hline Cereal & 1.874 & 423,5 & 46,9 & 425,0 & 58,1 \\
\hline Viñedo & 2.082 & 478,7 & 53,0 & 306,0 & 41,9 \\
\hline Lleco & 17 & 1,2 & 0,1 & & \\
\hline Total & 3.977 & 903,9 & & 731 & \\
\hline
\end{tabular}

* El cereal incluye los llecos y la huerta.

10. Las cifras que se consignan para 1881 han sido profusamente utilizadas por todos los estudiosos del mundo agrario. Los últimos han sido Ibáñez, S. y Alonso, J.: "Especialización agraria..." y Barco, E.: Del "oidium" a la edad de oro... 


\begin{tabular}{|l|r|r|r|r|}
\hline Logroño & Superficie* & $\%$ & 1881 & $\%$ \\
\hline Cereal & $2.887,4$ & 65,1 & $3.612,3$ & 82,7 \\
\hline Viñedo & $1.161,2$ & 26,2 & 381,7 & 8,7 \\
\hline Olivar & 386,0 & 8,7 & 373,9 & 8,6 \\
\hline Total & $4,434,6$ & & $4.367,9$ & \\
\hline
\end{tabular}

* La superficie no coincide con la que aparece en el cuadro 3 porque no se han incluido ni las arboledas ni los pastizales.

\begin{tabular}{|l|r|r|r|r|r|}
\hline Treviana & Parcelas & Superficie & $\%$ & 1881 & $\%$ \\
\hline Huerta & 76 & 3,8 & 0,2 & & \\
\hline Cereal & 3.075 & $1.158,5$ & 70,4 & $1.551,0$ & 75,1 \\
\hline Viñedo & 2.002 & 478,1 & 29,1 & 513,0 & 24,9 \\
\hline Otros & 47 & 5,0 & 0,3 & & \\
\hline Total & 5.200 & $1.645,4$ & & $2.064,0$ & \\
\hline
\end{tabular}

En Azofra el crecimiento de la superficie vitícola no se produce a costa de la tierra dedicada a cereal, sino que se realiza sobre nuevas tierras, roturaciones ganadas a los eriales, los restos del comunal, márgenes de caminos, etc. La productividad de estas nuevas tierras no debía ser muy alta, pero los elevados precios que se estaban pagando por la uva, en un momento de euforia exportadora, hacía rentables estas explotaciones, a lo que hay que añadir que la mayoría de ellas, tal y como reflejaba la distribución del amillaramiento, estaban en manos de pequeños propietarios que podían sobreexplotar su propio mano de obra familiar, sin necesidad de acudir a la mercado de trabajo para la contratación de jornaleros que, inevitablemente, reducirían su margen de beneficio"1.

Por el contrario, en la ciudad de Logroño el crecimiento de la vid se produjo en detrimento de otros cultivos, especialmente el cereal. Esto puede estar indicando el hecho de que las posibilidades de incrementar la superficie agraria útil del término municipal no existieran, pues las zonas susceptibles de ser incorporados a la cultura adolecían de una evidente falta de calidad. Aunque también en el caso de Logroño, la posibilidad de plantar viñedo en zonas regables hacia que el cambio de cultivos en estas zonas fuera continuo y los propietarios prefirieran modificar éste que no roturar zonas marginales de más bajos rendimientos y similar inversión en mano de obra, lo que reducía, por supuesto, el margen de beneficio. Entre 1881 y 1892 la disminución del cereal regable es escasamente de doscientas hectáreas, mientras que el que se plantaba en secano se redujo en seiscientas hectáreas. Estas ochocientas hectáreas son aproximadamente las que ganó entre ambas fechas el cultivo de la vid.

11. El $64 \%$ de las parcelas y el $50 \%$ de la superficie vitícola estaba en manos de los propietarios que declaran menos de ocho hectáreas, lo que parece confirmar el carácter minifundista de las roturaciones. 
De los datos aportados por los tres amillaramientos y su comparación con las cifras de 1881, sólo los de Treviana no sirven para extraer algunas conclusiones, fundamentalmente las que se refieren a la imparable extensión del viñedo observada tanto en Logroño como en Azofra. Esta tendencia parcial se verá confirmado en el siguiente apartado, cuando comparemos las cifras globales de los totales provinciales, tal y como se reflejaron en algunas encuestas de la época. Las cifras que se comentan a continuación han sido ya todas ellas publicadas, por lo que no van a ser sometidas a ninguna crítica, ni van a suscitar ningún recelo.

\section{III.1. Superficie agraria en La Rioja}

El sector agrario riojano estuvo, al menos desde el siglo XVI, más orientado hacia el mercado que hacia el autoconsumo, más hacia la producción de excedentes de unos determinados productos que a la ocupación del suelo con los cultivos básicos para la supervivencia de la unidad familiar. El campo se repartía entre el cereal y el viñedo y durante toda la edad moderna, La Rioja fue deficitaria en cereales panificables, pero las superficies dedicadas a la uva no desaparecieron, sino que por el contrario crecieron, para alcanzar sus dos máximos a fines del siglo XVI y del XVIII, respectivamente. La revolución agraria liberal, una radical transformación del estatuto jurídico de la tierra, no modificó en absoluto esta tendencia, sino que algunos adelantos del siglo, principalmente el ferrocarril, permitieron un nuevo empuje a la agricultura mercantilizada, iniciándose también un poderoso sector agroindustrial, que se beneficiaba de las zonas de huerta regables, cercanas al río Ebro. Conforme los transportes se fueron haciendo más rápidos y seguros, la especialización se incrementó.

Las cifras que se muestran en el cuadro 6 y que se representan visualmente en el gráfico 4, servirán, al menos, para establecer algunas líneas generales en la evolución del sector agrario riojano entre mediados del siglo XIX y la II República.

En primer lugar nos fijaremos en la evolución general de la superficie de tierra labrada de la provincia, referida exclusivamente a aquellos frutos más directamente vinculados a la agricultura, excluyendo así las superficies que se dedicaban a pastos, tanto praderas artificiales como pastos naturales y las que se dedicaban a monte.

El crecimiento es constante entre 1861 y 1900 , año en el que se consigue la máxima superficie de tierra labrada de todo el periodo de estudio. Entre esas fechas, la población activa agraria se había mantenido estable en torno al $70 \%$, pasando de 45.000 activos a 49.000 , con un máximo en 1887 , año en el que se registraron casi 53.000 trabajadores de la tierra. Esto quiere decir que si en 1861 a cada trabajador le correspondía un laboreo de tres hectáreas, en 1900 esta superficie se había incrementado hasta las cuatro. El aumento de la super- 
ficie agraria supuso, entre otras consecuencias, la utilización más intensiva, si cabe, del factor trabajo como una de las fórmulas más eficaces para extraer a la tierra un mayor margen de beneficio, pues como Domingo Gallego señala en sus trabajos ya citados, la ampliación de la superficie agraria no se acompañó de mejoras técnicas, tanto en utilización de abonados como de maquinaria.

Cuadro 6. Superficies agrarias. La Rioja, 1861-1931

\begin{tabular}{|l|r|r|r|r|r|r|r|}
\hline & \multicolumn{1}{|c|}{1861} & \multicolumn{1}{|c|}{1881} & \multicolumn{1}{c|}{1890} & \multicolumn{1}{c|}{1900} & 1910 & 1922 & \multicolumn{1}{c|}{1931} \\
\hline Cereal & 97.145 & 106.568 & 102.035 & 138.083 & 139.952 & 121.122 & 117.555 \\
\hline Viñedo & 26.595 & 35.676 & 52.392 & 49.000 & 22.630 & 29.544 & 29.870 \\
\hline Olivar & 4.877 & 5.869 & 6.203 & 8.390 & 8.364 & 5.850 & 5.064 \\
\hline Frutal & 124 & 0 & 0 & 0 & 14 & 19 & 245 \\
\hline Raíces & 0 & 0 & 0 & 3.018 & 3.381 & 4.910 & 3.811 \\
\hline Plantas Ind. & 0 & 0 & 0 & 61 & 230 & 1.850 & 3.607 \\
\hline Huerta & 5.083 & 0 & 0 & 0 & 1.874 & 2.175 & 2.489 \\
\hline TOTAL & 133.824 & 148.113 & 160.630 & 198.552 & 176.445 & 165.470 & 162.641 \\
\hline
\end{tabular}

* Elaboración propia. Fuentes, para 1861 y 1881, Barco, E.: Del "oidium" a la edad de oro..., para las demás fechas, Gallego, D.: "El sector agrario riojano..."

Si analizamos ahora los datos desagregados por cultivos podremos enriquecer más el estudio. En primer lugar destaca el hecho de que durante el siglo XIX solo se reflejaran en las estadísticas agrarias los cultivos de la denominada trilogía mediterránea: cereal, vid y olivo, con circunstanciales superficies dedicadas a otros productos. Cultivos tradicionales, puede pensarse, pero si observamos su evolución en el tiempo podremos apreciar que el "inmovilismo" campesino no es sino una vieja imagen de debates historiográficos hoy superados.

El sistema cereal era el mayoritario en la comunidad, ya que ocupó casi durante todo el periodo entre el $70 \%$ y $80 \%$ de la superficie agraria útil. Pero fue el que menos modificaciones sufrió. Sus variaciones son siempre muy discretas, oscilando en una banda entre el índice 100 de 1861 y el máximo 144 en 1910. Posiblemente la tierra no daba para más y expansiones más ambiciosas hubieran conducido inevitablemente a los rendimientos decrecientes, pues el cereal, siguió siendo un cultivo atractivo, sobre todo después del arancel Salvador de 1906, que elevó de forma artificial el precio del trigo nacional. Ante la certeza de que más extensión no tenía que traducirse necesariamente en mayor beneficio, los agricultores riojano optaron por mantener la superficie y buscar las alternativas en otros cultivos.

La vid jugó ese papel alternativo durante toda la segunda mitad del siglo XIX. Con una masa de viñedo casi destruida totalmente después de la guerra de la independencia, la superficie no empezó a recuperarse hasta los años cincuenta, al menos veinte años antes de lo que se creía. Entre 1855 y 1861 la superficie se incrementó en dos mil hectáreas y entre esa última fecha y 1881 
en otras diez mil. La conquista de nuevos mercados es la causa natural de esta evolución expansiva y los años dorados, entre 1880 y 1900, la culminación de una época que sólo ahora, en los últimos años del siglo XX está volviéndose a repetir. El índice casi llegó a doblarse en 1890, para retroceder desde entonces. En el peor momento, 1910, la masa de viñedo era inferior a la de 1861 y también a la de 1855. En diez años se había sacrificado algo más de la mitad de la superficie. Los principales perjudicados fueron los viticultores, como veremos en su momento.

El olivar mantuvo una constante alza de sus superficies, que aún no alcanzando nunca el $5 \%$ del total tenía una gran importancia en la comarca arnedana, principalmente. Su tendencia se mantuvo hasta 1910 año en el que comienza su lento declinar. Parece que mientras en Andalucía se supo transformar a tiempo la industria aceitera, en La Rioja, al ser más marginal, los afectados no tuvieron las ganas o el capital necesarios para acometer semejante reconversión.

El resto de aprovechamientos jugaron un papel secundario. Sólo a partir de 1900 comienzan a aparecer en los censos agrarios y en 1930 representaban en conjunto el $6,2 \%$ de la superficie de tierra labrada. De entre ellos el incremento más espectacular lo protagonizó la remolacha -englobada en plantas industriales- pues llegó a alcanzar un índice 6.000 en 1930, aunque obvio es el decirlo, comenzó con unas pocas decenas de hectáreas declaradas en 1900. También la patata se abrió un hueco importante en algunas zonas. Ambos cultivos requerían buenos cuidados, regadío y una cultura alejada de lo extensivo. El campesino adaptativo hizo pronto su aparición en La Rioja.

Por último la encuesta agraria de 1881 nos permite un acercamiento más localizado a la realidad agraria riojana, pues los datos los podemos desagregar por partidos judiciales y por términos municipales.

Las ocupaciones del suelo presentaban una clara especialización por zonas. El cereal se concentraba en las llanuras del oeste, siendo en el partido judicial de Santo Domingo de la Calzada donde se encuentra una mayor concentración de ese aprovechamiento ${ }^{12}$. Después venía el partido de Logroño, donde el regadío y unas condiciones para la agricultura excelentes, hacían de esta comarca una de las más aptas para todo tipo de cultivos, pues sin destacar en ninguno, de todos ellos tenía en proporciones nada despreciables. El resto de los partidos tenían una menor presencia, aunque tanto Alfaro como Calahorra mantenían porcentajes respetables de tierra dedicados al sistema cereal, que por lo demás era mayorita-

12. Si midiéramos exclusivamente las superficies declaradas, las mayores extensiones se daban en el partido de Nájera, pero se ha introducido un índice corrector en el que se considera también la superficie total del partido judicial, pues no son lo mismo 17.000 hectáreas repartidas en 100.000 , que 16.000 en la mitad de extensión. La sensación para el viajero sería la de que era mucho más importante el cereal en el segundo caso que en el primero. 
rio en todos los partidos, y único cultivo declarado en el partido de Torrecilla, donde alternaba con explotaciones madereras y pastizales para ganado.

El viñedo tenía su zona privilegiada en el partido de Haro, donde más de la mitad de la superficie agraria se dedicada a su laboreo. Representaba también aproximadamente un $40 \%$ de la superficie total provincial. A considerable distancia le seguían los partidos de Logroño y Nájera, con porcentajes de vid mucho más modestos.

El tercer componente de la trilogía, el olivo, encontraba su acomodo natural en el partido de Arnedo, donde se situaba casi la mitad de las seis mil hectáreas declaradas. Le seguía nuevamente Logroño, donde se trabajaba aproximadamente un cuarto de la superficie total del aprovechamiento.

Esta rápida visión nos ofrece una imagen de clara especialización en la provincia, con zonas delimitadas para los distintos cultivos y donde solo el eclecticismo del partido de Logroño permite hablar de verdadero policultivo, lo que le hacía ser la zonas agrícola mas equilibrada y rica de la provincia, pues las demás estaban demasiado sujetas a los vaivenes en los mercados de sus respectivos productos.

El mapa 1, por último, nos permite una constatación necesaria, los porcentajes de superficie de tierra labrada sobre el total del la extensión del partido judicial.

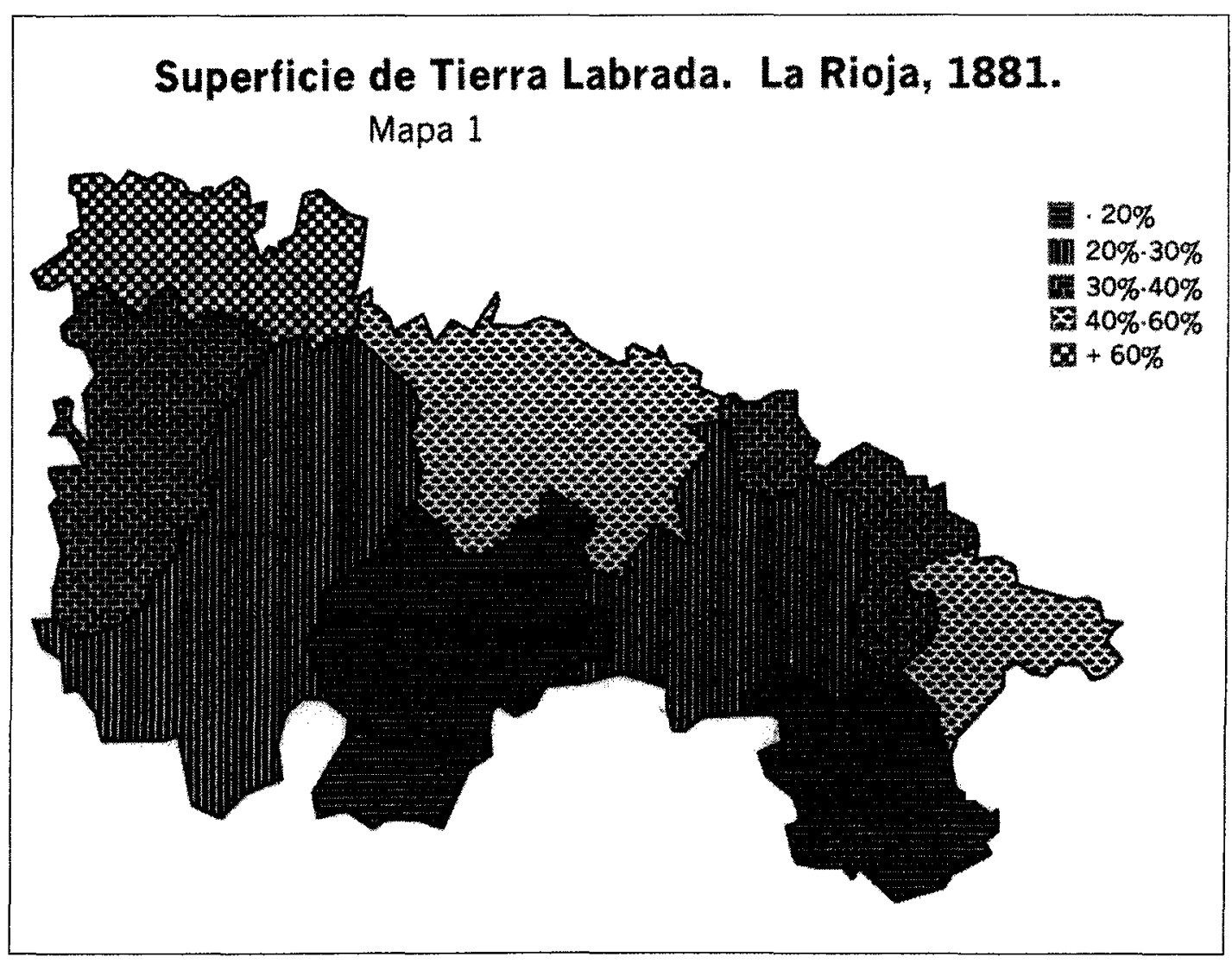


De acuerdo al mapa, en el partido de Haro era donde se ejercía una mayor presión sobre la tierra, pues aprovechaba el 60\% del terrazgo. Si tenemos en cuenta las superficies que ocupaban caminos, cascos urbanos, el río Ebro y sus afluentes... hemos de concluir que poca tierra estaba sin trabajar. A esto ayudaba el que el cultivo principal fuera la vid, poco exigente en cuanto a la bondad del lecho que la acoge y que podía subsistir en laderas, bancales, eriales, etc, aunque sus rendimientos, lógicamente, no igualaran a las plantaciones que descansaban sobre mejores tierras. Luego se dibuja una zona clara en los partidos del valle, con ocupaciones en torno al $40 \%$ del total. Alfaro, Logroño y Calahorra, por este orden, disfrutaban de importantes zonas regables, terreno casi llano y condiciones favorables para la práctica de la agricultura.

Santo Domingo y Arnedo son zonas de transición, con una parte considerable que se interna en la sierra. Aún así sus porcentajes de ocupación estaban en torno al 30\%. Nájera era un partido judicial particular. El de mayor extensión de la provincia y con su zona sur situada en plena sierra, lo que reducía drásticamente los porcentajes de ocupación de los pueblo situados más al norte. Municipios como Alesanco, Berceo, Bobadilla, Cordovín, Huércanos, Torrecilla sobre Alesanco y Tricio, superaban todos ellos el $80 \%$ de ocupación, mientras que otros como las Viniegras, de Arriba y de Abajo, Canales de la Sierra o Mansilla apenas si llegaban al $2 \%$. Con estas diferencias tan enormes no resulta difícil comprender lo escaso del terreno cultivable del partido en su conjunto, que apenas superaba el $20 \%$. Por último tanto Cervera del río Alhama como Torrecilla en Cameros eran zonas propiamente de sierra, con utilizaciones agrarias muy pobres, centradas fundamentalmente en el cereal.

En conclusión, La Rioja había ido adaptando su agricultura a lo largo del siglo XIX y primer tercio del XX a las cambiantes coyunturas de mercado, a la vez que se producía en su interior un proceso de especialización comarcal, que aunque coherente con las máximas productivistas de la burguesía de la época, fue abandonando a su suerte a porciones importantes de la provincia, peor dotadas para una agricultura cada vez más intensiva en trabajo y capital, con unas mayores exigencias de calidad y con el mercado como objetivo final. Esas zonas fueron despoblándose paulatinamente, a la vez que se producía una excesiva concentración en las cercanías del valle. Dentro de su pequeñez territorial la provincia puso en ese periodo las bases para un crecimiento totalmente desarticulado, creando una fractura social difícilmente subsanable. Sólo hoy, en 1999, cuando los "urbanitas" recorren en sus todo terrenos las zonas serranas, un pálido reflujo, un miserable retorno, una patética recompensa se está realizando sobre quienes fueron los sacrificados por un determinado modelo de modernización y crecimiento económico. 


\section{La filoxera}

Para comprender con exactitud la magnitud de la catástrofe filoxérica es necesario que antes conozcamos, aún muy brevemente, la situación del viñedo riojano con anterioridad al 5 de junio de 1899, día en que se detectó la plaga en un viñedo de la localidad riojalteña de Sajazarra.

El sector vitivinícola había alcanzado un extraordinario desarrollo gracias a la apertura de los mercados europeos, sobre todo el francés, desde mediados del siglo XIX. Las viejas elaboraciones de los campesinos cosecheros, un vino sucio, de sabor desagradable, y lo que es más importante, sin posibilidad de ser conservado más allá del año, había dado paso a la introducción de técnicas de vinificación más avanzadas, puestas en práctica por burgueses ennoblecidos como el Marqués de Murrieta o el Marqués de Riscal, verdaderos próceres de las modernas bodegas de elaboración de vinos finos. Pero estos procedimientos innovadores, apenas si tuvieron importancia cuantitativa, pues la "edad de oro" del viñedo riojano, entre 1870 y 1892 aproximadamente, se basó en la exportación a Francia de caldos sin elaborar, vinos a granel que luego eran tratados en las bodegas bordelesas para darles su inconfundible bouquet francés ${ }^{13}$.

La expansión de la superficie de viñedo fue espectacular en esos años. Como ya se ha visto, entre 1861 y 1890 se duplicó la extensión agrícola dedicada a los cultivos leñosos. La máxima superficie que ofrecen todos los estudiosos, 52.392 hectáreas peca de una enorme vaguedad cronológica, pues Oestreicher la fija en 1889, Provedo la encuentra en una memoria de 1912, referida a finales de siglo y Gallego la ofrece para el censo de 1890. Parece que la coincidencia de Gallego y Oestreicher puede fijar la cifra en 1890 y permitirnos algunas comparaciones. Para empezar, aclarar la verdadera naturaleza de esa superficie con un dato actual, en 1998 no se habían alcanzado las 37.000 hectáreas de superficie cultivada, aunque lógicamente los rendimientos sean muy distintos ahora y hace un siglo. Una verdadera "fiebre" es lo que recorrió la provincia durante aquellos años, en los que cualquier erial era bueno para plantar una cepas. Las cifras comparativas entre 1881 y 1890 nos hablan de un incremento superficial de 17.000 hectáreas, un 47,4\% más en apenas diez años. Por partidos judiciales, el que más incrementó la masa de viñedo fue Santo Domingo, que duplicó su superficie, seguido de Nájera y Calahorra. Pero estos años de exportaciones cada vez mayores iban a finalizar antes de la aparición de la filoxera.

La recuperación vitivinícola francesa era un hecho al comienzo de la década de 1890 y la presión de los cultivadores galos sobre su gobierno para frenar las importaciones no cesaron hasta que se plasmaron en la firma del nuevo tratado comercial entre la República de Francia y el Reino de España de 1892, que cerraba las puertas del mercado francés al vino español. La Rioja se encontra-

13. Oestreicher, A.: "Algunos aspectos de la historia...". 
ba de golpe con un sector sobredimensionado y una producción que no sabía donde colocar. La crisis, por lo tanto, se inició unos años antes de la presencia del insecto en nuestras tierras. Pero esta era una crisis de mercados y debía resolverse en los mercados. La única consecuencia práctica de la pérdida del mercado francés fue la reducción en unas 3.000 hectáreas de la superficie plantada, si hemos de creer las cifras de los censos de 1890 y 1900, aunque en 1902 se volvieron a declarar unas 52.500 hectáreas.

Tal y como han demostrado convincentemente Oestreicher y Gallego en sus trabajos, el arancel de 1892 permitió la verdadera transformación del sector vitivinícola riojano. El proteccionismo mutuo llevó a que cada país reservase para sus caldos los mercados locales y los bodegueros riojanos fueron los que con más acierto empezaron a colocar en las mesas de las ciudades sus productos: vinos finos, elaborados al gusto francés, pero con uvas autóctonas. Así, mientras los precios de las materias primas bajaban, el beneficio empresarial de estos productores crecía, pues habían conseguido reemplazar en corto periodo de tiempo una mercado por otro. Esa es la razón del extraordinario incremento en la creación de empresas bodegueras entre 1890 y 1900 en la Rioja Alta, en torno a Haro principalmente ${ }^{14}$. Mientras tanto los campesinos veían como sus márgenes se reducían cada vez más, pues el vino de pasto no era tan apreciado y tenía enormes problemas para ser colocado en los mercados.

En este contexto las alternativas para los viticultores eran escasa, iniciar una paulatina reducción de la superficie para adecuarla a las nuevas realidades e impedir que el precio de la uva cayera aún más. En esta necesaria reconversión tuvieron un aliado inesperado, la filoxera, que en unos pocos años redujo drásticamente la superficie agraria dedicada a la producción de mostos ${ }^{15}$.

La filoxera arruinó aproximadamente el $85 \%$ de la superficie. De las 52.000 hectáreas que había en 1890 se pasó a 8.400 en 1909, pues el resto hasta las 22.630 que se ofrecen en la estadística estaban atacadas por el parásito y por lo tanto con su capacidad productiva muy mermada. Como puede comprenderse esta drástica reducción de superficies arruinó durante años la economía agraria riojana y por extensión, la actividad económica global de la provincia. Estos fueron los costes de una excesiva especialización en un producto destinado exclusivamente para el mercado y que no podía ser reutilizado, ni consumido por los productores.

Los agricultores fueron los más perjudicados, pues vieron como se arruinaban sus propiedades y no podían hacer frente a los elevados costes de la replantación. La importación de la cepa americana, variedad más resistente y que ya

14. Vease mi colaboración en el trabajo de próxima publicación " 75 años de Consejo Regulador de la Denominación de Origen Rioja" sobre esta misma etapa histórica.

15. Provedo explica perfectamente la lucha contra la filoxera, el papel de las instituciones y de los particulares, las peculiaridades fitosanitarias, etc., por lo que aquí me voy a centrar en explicar, exclusivamente, el impacto social que tuvo en el campo riojano la plaga. 
había demostrado su adaptación a los terrenos europeos en la vecina Burdeos, era muy cara y las ayudas oficiales no alcanzaban para soportar los costes financieros de la operación. Además, la posibilidad de orientar la tierra hacia otros cultivos no existía en la mayoría de las ocasiones, pues el viñedo se situaba generalmente en zonas de secano de mediocres calidades. Los cereales no eran una opción y mucho menos otro tipo de cultivos que necesitaban el regadío. Era viñedo o nada. El resultado, una ola de emigración como no se había conocido en la provincia hasta entonces y no se ha vuelto a conocer después. El mapa 2 muestra perfectamente la evolución de la población riojana entre 1900 y 1920 , desagregada por partidos judiciales. En él se puede apreciar como en aquellas zonas donde la presencia del viñedo era considerable, la población retrocedió, siendo el caso más paradigmático el partido de Haro, que fue el que más población perdió durante todo este periodo. Lógicamente, el retroceso demográfico del partido de Torrecilla debe interpretarse bajo otros parámetros ${ }^{16}$.

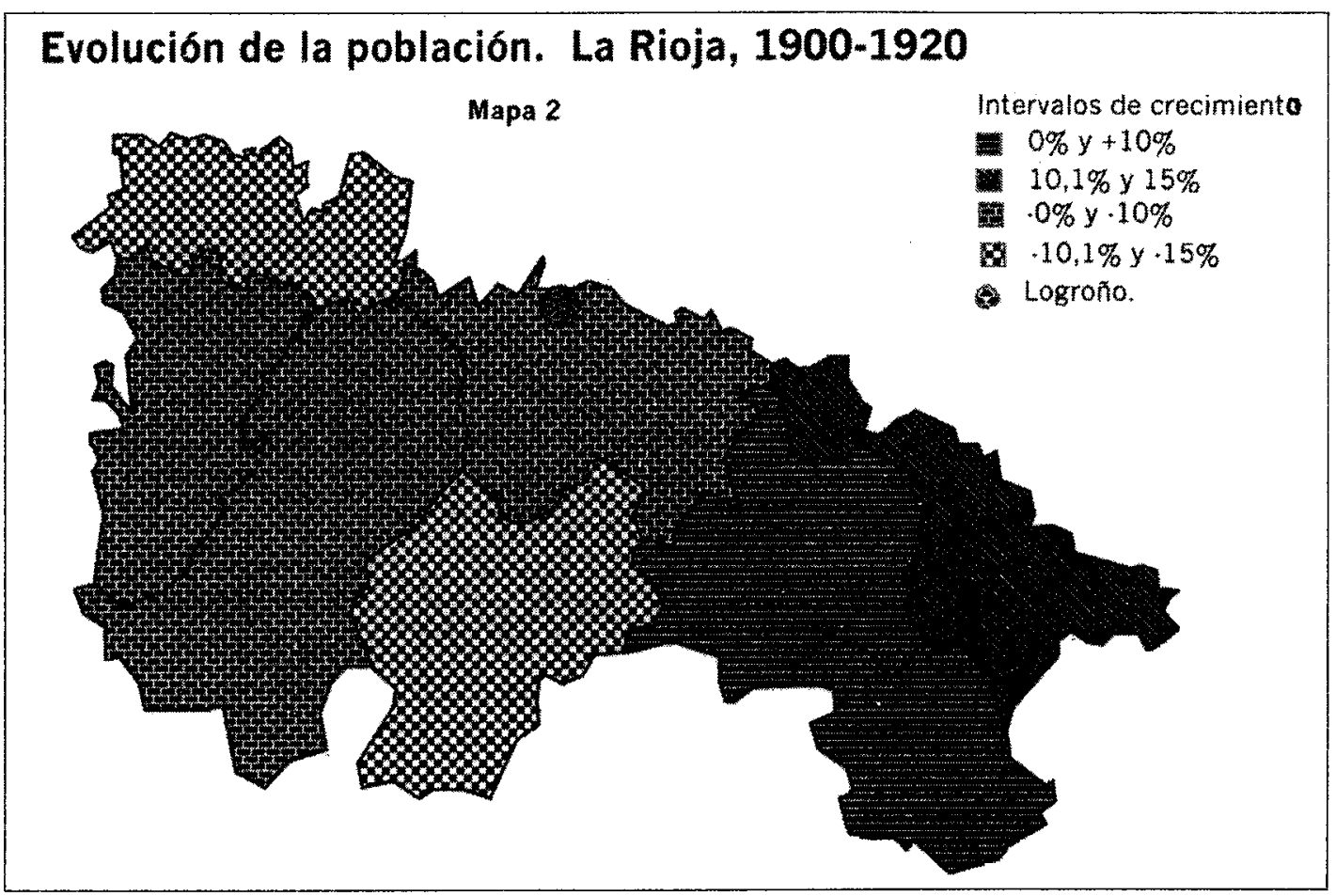

El resto de actividades económicas fue incapaz de absorber la mano de obra excedente. Mientras los bodegueros seguían acumulando beneficios, pues el que no hubiera materia prima en La Rioja no significaba que ellos dejaran de producir caldos finos, pues la inexistencia de organismos controladores permi-

16. Más información sobre la emigración y su evolución en la demografía riojana puede encontrarse en mi trabajo inédito "La población riojana de fin de siglo" en el proyecto de investigación ya citado La Rioja ante la crisis de fin de siglo. 
tía la libre circulación de mostos por la península. No debe extrañarnos que en la primeras décadas del siglo XX fueran los agricultores los que con más fervor defendieran la creación de Denominaciones de Origen que controlaran esos flujos, ilícitos según ellos. Sin embargo, la falta de opciones empujó a los propietarios a reiniciar una costosísima replantación, que abandonó al resto de cultivos a su suerte: quizás quién más sufrió las consecuencias fuese el olivar, que vio como se reducían sus superficies y rendimiento durante este periodo. También el cereal atravesó una fase de estancamiento, tanto en superficies como en rendimientos. Todas las energías se concentraron en la reconstrucción de la masa de viñedo. Durante veinticinco años en la provincia no se pensó en otra cosa. Esta actitud, que podía parecer suicida teniendo en cuenta lo que acaba de suceder tiene su sencilla explicación: el cultivo del viñedo seguía siendo remunerador, ya que después de la caída de precios de la década de 1890 se había estabilizado y se mantuvo así hasta la guerra civil. Lo único que se hizo fue abandonar aquellas plantaciones que sólo eran rentables en coyunturas alcistas muy determinadas. Para 1925 se puede dar por concluida la replantación. La superficie en ese momento rondaba las treinta mil hectáreas, aproximadamente un $60 \%$ del la superficie máxima de 1890 .

Otro indicador nos puede ofrecer información adicional sobre el impacto de la crisis. El valor de la producción de los viñedos pasó de treinta y un millones de pesetas en el año 1890 a tan solo dos y medio en 1910, lo que pudo suponer una reducción del $38 \%$ del valor del producto agrario en su conjunto y de un $44 \%$ del agrícola ${ }^{17}$. Lógicamente el incremento de la participación de otros productos frenó algo ese impacto. Esta drástica reducción de ingresos no pudo ser compensada con otras entradas, en un momento de transformación profunda del mundo agrario español en su conjunto.

La zona más afectada fue la que más decididamente había apostado por la especialización. El partido judicial de Haro sufrió un retroceso en todas sus facetas de la que sólo llegó a recuperarse recientemente. Si el conjunto de La Rioja había reequilibrado su economía agraria para 1930, sobre todo gracias a la facilidad de las zonas regables de rioja baja para adaptarse a la cambiantes coyunturas, la zona vitivinícola de rioja alta mantuvo estancado su crecimiento durante algunas décadas más. Por el camino quedaron los trabajadores emigrantes, los propietarios arruinados y los insurrectos que aún pretendían proclamar en la cuenca del Ebro el comunismo libertario.

\section{Conclusiones}

Como ha podido desprenderse de estas páginas también La Rioja tuvo su crisis finisecular. No fue en este caso un cataclismo colonial, la pérdida de una

17. Gallego, D.: "El sector agrario riojano...", p. 55. 
tradicional imagen imperialista, ni tan siquiera la crisis de un sistema de gobierno, aunque uno de sus pilares fuera riojano.

La crisis riojana fue estrictamente económica. Fue el resultado de una orientación suicida hacia una especialización excesiva en un solo producto, alentado por las instituciones provinciales, los inversores, comisionistas, especuladores y gentes de toda laya que vivían del trabajo del campesino. Fue una crisis que rompió la utopía del crecimiento continuo, del beneficio desmedido, de la acumulación ininterrumpida.

Quizás fuera bueno, que ahora que se cumplen cien años de la aparición de la plaga filoxérica, los riojanos reflexionaran sobre la orientación que esta tomando en este fin de siglo la actividad agraria, donde nuevamente el viñedo esta alcanzando un protagonismo desmedido, aupado por una coyuntura que ha roto todas las expectativas y los ciclos que hasta ahora habían acompañado al sector y lo hacían fácilmente predecible. La continua expansión de la superficie agraria, las cosechas abundantes, y los mercados que adquieren el vino incluso antes de que esté elaborado, recuerdan demasiado a esa otra "edad de oro" que tuvo lugar hace ciento diez años.

No es labor del historiador ser apocalíptico, sino ofrecer a sus conciudadanos los materiales históricos necesarios para que pueda formarse una opinión de lo que pasó y de lo que puede volver a ocurrir. No es el historiador quien debe tomar decisiones, pero faltaría a su compromiso cívico si hurtase o edulcorase las realidades históricas pretéritas, por muy duras o negativas que estas pudieran parecer.

La provincia de La Rioja sufrió su crisis más profunda y duradera por la conjunción de una serie de factores vinculados todos ellos al mundo vitivinícola. $Y$ esto aconteció hace exactamente cien años, cuando nuestra tropas perdían las últimas colonias de un imperio caduco y la metrópoli caminaba, con paso muy lento y titubeante hacia su inmersión en el mundo capitalista del siglo XX. 


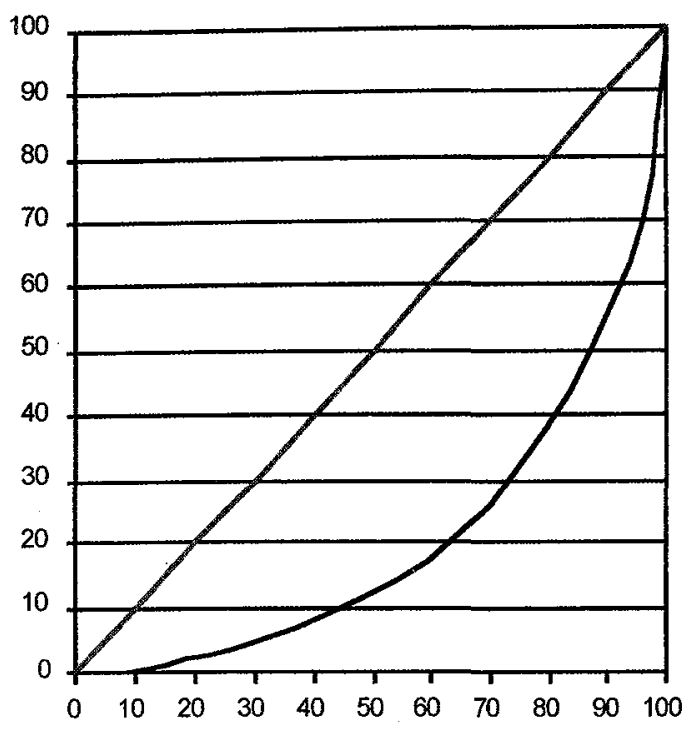

Gráfico 1

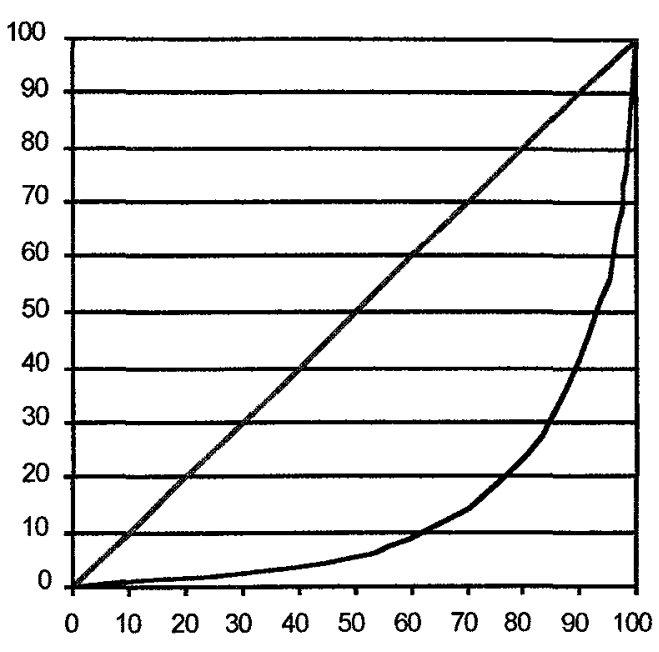

Gráfico 2
Curva de Lorenz. Logroño, 1892

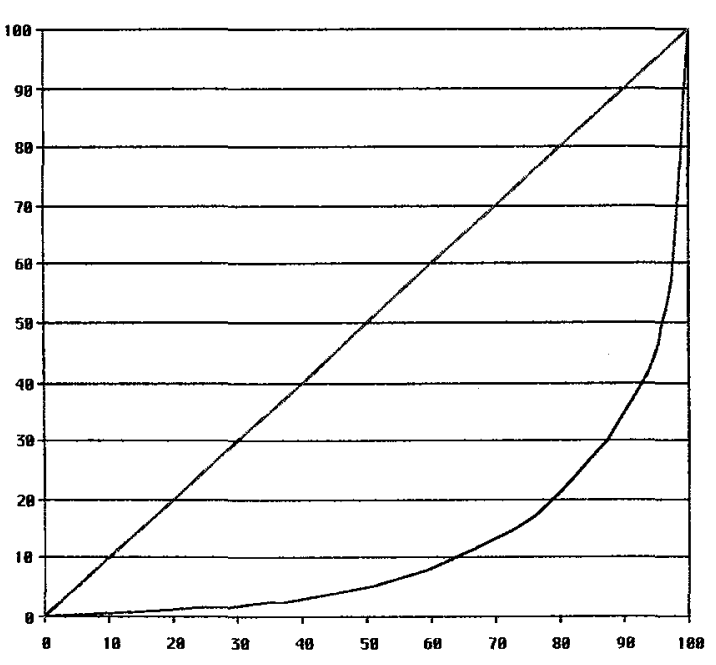

Gráfico 3
Superficies agrarias. La Rioja.

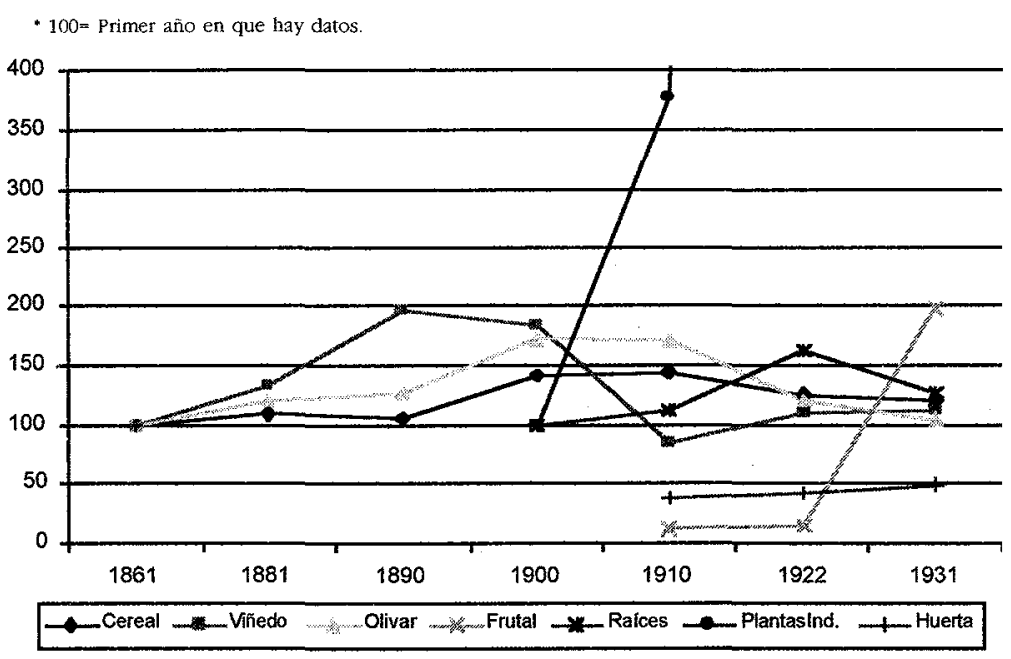

Gráfico 4 